\title{
LOS ESCRITOS DE EMILE DURKHEIM EN ESPAÑOL: RESEÑA BIBLIOGRÁFICA
}

\author{
Gonzalo Cataño
}

Universidad Pedagógica Nacional, Bogotá (Colombia)

Esta bibliografía pretende ser exhaustiva. Sin embargo, cabe recordar que las traducciones del autor de Le suicide al castellano son múltiples y dispersas. Muchas de ellas no han superado las fronteras nacionales y no pocas se han extraviado en revistas y ediciones de escasa circulación que sólo han llegado a manos de círculos muy restringidos de iniciados. Con frecuencia vemos que un mismo texto presenta varias versiones y que ellas se han realizado sin tener en cuenta las anteriores. Generalmente, los traductores latinoamericanos y españoles han emprendido su tarea con la sensación de estar trabajando en un terreno virgen, hecho que ha impedido un esfuerzo acumulativo del traslado de las obras de Durkheim al castellano. A diferencia del mundo anglosajón, donde las nuevas traducciones parten de una evaluación crítica de las anteriores, en el mundo hispanoamericano la lectura del sociólogo francés se ha basado en un conjunto de versiones aisladas que no permiten establecer con facilidad su diversa calidad.

Es posible que esta situación cambie con el renovado interés que en los últimos años ha cobrado la figura de Durkheim en América Latina y España. Ahora se escriben libros y ensayos sobre su obra en español, y algunos de los Departamentos de Sociología consagran seminarios enteros a la discusión y estudio de su pensamiento. Pero todavía se carece de un inventario seguro de las múltiples traducciones que circulan en uno y otro país y apenas sabemos cuáles son las más recomendables. La presente bibliografía busca llenar de 
alguna manera este vacío. Registra la difusión de la obra del fundador de la escuela francesa de sociología a través del mundo hispánico, y ofrece la materia prima para el obligado balance crítico de las copiosas versiones castellanas. Debe anotarse, sin embargo, que todos los libros de Durkheim — tanto los publicados en vida como los póstumos y los compilados por sus alumnos- se encuentran disponibles en español. Sólo faltan por traducir algunos de sus ensayos sueltos, especialmente los juveniles; sus numerosas recensiones bibliográficas, sus escritos etnográficos — de los cuales hay apenas unas pocas muestras en español- y sus trabajos acerca del contenido y alcance de las ciencias sociales.

Esta bibliografía se ha organizado siguiendo la secuencia de la aparición de los textos de Durkheim en español. El año antes del corchete registra la primera edición castellana, y la fecha entre corchetes alude a la publicación original en francés. Un registro completo de los libros y ensayos de Durkheim se encuentra en Steven Lukes, Emile Durkheim: su vida y su obra (Madrid: Siglo XXI, 1984), pp. 552-577, y en Emile Durkheim, Textes (París: Minuit, 1975), vol. III, pp. 487-541. Ambas bibliografías constituyen una ampliación y actualización del antiguo inventario realizado por Harry Alpert en su libro, de 1939, Durkheim and His Sociology (trad. cast.: H. Alpert, Durkheim, México: Fondo de Cultura Económica, 1945, pp. 264-273).

\section{LIBROS}

1912 [1895] Las reglas del método sociológico (Madrid: Daniel Jorro). Trad. de Antonio Ferrer y Robert. Algunos problemas de traducción de esta edición, considerada la clásica en español, fueron consultados con el mismo Durkheim. Después de esta versión se han publicado múltiples traducciones tanto en España como en América Latina. Una muestra de ellas son:

- Las reglas del método sociológico (Santiago de Chile, 1937). Trad. de J. Meza.

- Sociología (Córdoba, Arg.: Editorial Assandri, 1961). Edición a cargo de Alfredo Poviña, siguiendo la traducción de Antonio Ferrer y Robert.

- Las reglas del método sociológico (Buenos Aires: Editorial Schapire, 1965). Trad. de Paula Wajsman.

- Las reglas del método sociológico (Madrid: Ediciones Morata, 1974). Trad. de L. V. Echavarría.

- Las reglas del método sociológico (Buenos Aires: Editorial La Pléyade, 1976). Trad. de Aníbal Leal.

- Las reglas del método sociológico (México: Fondo de Cultura Económica, 1986). Trad. de Ernestina de Champourcín. 
- Las reglas del método sociológico y otros escritos sobre filosofía de las ciencias sociales (Madrid: Alianza Editorial, 1988). Trad. de Santiago González de Noriega.

1915 [1915] ¿Quién ha querido la guerra? Los origenes de la guerra según los documentos diplomáticos, en colaboración con E. Denis (París: Librairie Armand Colin). Trad. de C. Docteur.

1915 [1915] "Alemania por encima de todo": la mentalidad alemana y la guerra (París: Librairie Armand Colin). Trad. de P. Salinas. Publicado nuevamente por la Revista Española de Investigaciones Sociológicas, Madrid, enero-marzo 1989, pp. 199-228, con una introducción de Luis Rodríguez Zúñiga.

1928 [1893] La división del trabajo social (Madrid: Editorial Jorro). Trad. de Carlos G. Posada. Dos nuevas ediciones de esta traducción han sido publicadas por la Editorial Akal (Madrid, 1982), con un estudio preliminar de Luis R. Zúñiga, y por Planeta Colombiana (Bogotá, 1987, 2 vols.), dentro de su colección "Obras maestras del pensamiento contemporáneo». Una segunda versión española, a cargo de David Maldavsky, fue difundida por la Editorial Schapire, de Buenos Aires, en 1967.

1928 [1897] El Suicidio, con un estudio preliminar del traductor sobre la «Etiología del suicidio en España» (Madrid: Editorial Reus). Trad. de Mariano Ruiz-Funes. Esta versión ha sido publicada nuevamente por la Universidad Autónoma de México (México, 1974), con una introducción de Óscar Uribe Villegas, y por la Editorial Akal, de España (Madrid, 1976), con un estudio preliminar de Lorenzo Díaz Sánchez. Una segunda traducción, a cargo de Lucila Gibaja, fue difundida por la Editorial Schapire, de Buenos Aires, en 1965.

¿1930? [1928] El Socialismo, con una introducción del traductor (Barcelona: Editorial Apolo, s.f.). Trad. de Francisco Cañadas. No incluye la introducción de Marcel Mauss a la edición original francesa. La misma Editorial Apolo publicó una segunda y tercera ediciones en 1932 y 1934. Una segunda traducción, a cargo de Idea Vilariño, fue difundida por la Editorial Schapire, de Buenos Aires, en 1972. Esta edición incluye la introducción de Marcel Mauss, además del informativo prefacio de Pierre Birbaum a la publicación francesa de 1971. Sin embargo, el volumen es incompleto, dado que omite la segunda parte, dedicada a Saint-Simon. Una tercera traducción, auspiciada por la Editora Nacional (Madrid, 1982), se debe a Ramón Ramos Torre, cuya versión viene acompañada de un comprensivo estudio de la obra de Durkheim.

¿1931? [1922] Educación y sociología, con una introducción de Paul Fauconnet (Madrid: La Lectura, s.f.). Trad. de Alice Pestaña. Esta versión ha sido publicada en Colombia en dos ocasiones: la primera por Editora Babel (Bogotá, 1976) y la segunda por la Editorial Linotipo (Bogotá, 1979). 
Además de la introducción de Fauconnet, la edición colombiana incluye el prólogo de Talcott Parsons a la traducción inglesa de Education et sociologie. [Una edición pirata de la edición colombiana fue publicada en México — sin fecha- por la imprenta «Colofón».] Una segunda traducción, a cargo de Idea Vilariño, fue puesta en circulación en 1974 por la Editorial Schapire, de Buenos Aires. Y una tercera versión, auspiciada por Ediciones Península (Barcelona, 1975), se debe a Janine Muls de Liarás. Ésta incluye el prefacio de M. Debesse a la edición francesa de 1966 y un extenso epílogo de Joan Borrell sobre Jules Ferry y Durkheim.

1947 [1925] La educación moral, con una advertencia (incompleta) de P. Fauconnet (Buenos Aires: Losada). Trad. de María Luisa Navarro. Una segunda traducción, a cargo de Luis Liacho, fue difundida por la Editorial Schapire, de Buenos Aires, en 1973. Esta edición no incluye la advertencia de Fauconnet que acompaña el original francés.

1951 [1924] Sociología y filosofía, con un estudio preliminar del traductor y un prólogo de C. Bouglé (Buenos Aires: Editorial Kraft). Trad. de José María Bolaños.

1966 [1950] Lecciones de sociología (Buenos Aires: Editorial Schapire). Trad. de David Maldavsky (no contiene los prólogos de Huseyin Nail Kubali y Georges Davy que acompañan el original francés). Una segunda traducción, a cargo de Estela Canto, apareció bajo los auspicios de la Editorial La Pléyade, de Buenos Aires, en 1974. Esta edición incluye los prólogos de Kubali y Davy.

1968 [1912] Las formas elementales de la vida religiosa: el sistema totémico en Australia (Buenos Aires: Editorial Schapire). Trad. de Iris Josefina Ludmer. Una segunda traducción, auspiciada por la Editorial Akal (Madrid, 1982), se debe a Ramón Ramos Torre, cuya versión viene precedida de un esclarecedor estudio preliminar. Una tercera versión, a cargo de Santiago González Noriega, ha sido difundida por la Editorial Alianza, de Madrid (1993).

¿1968? [1912] Pragmatismo y sociología, con un prefacio de Armand Cuvillier (Buenos Aires: Editorial Schapire, s.f.). Trad. de Noe Jitrik.

1976 [1973] Educación como socialización, con una introducción de Nedo Baracani (Salamanca: Editorial Sígueme). Compilación italiana de lecciones, artículos y ensayos de Durkheim sobre educación y temas relacionados con los procesos de socialización. Trad. (del italiano) de Alfonso Ortiz García.

1982 [1938] Historia de la educación y de las doctrinas pedagógicas, con una presentación de Félix Ortega y una introducción de Maurice Halbwachs (Madrid: La Piqueta). Trad. de María Luisa Delgado y Félix Ortega.

1990 [1900-1916] Educación y pedagogía: ensayos y controversias (Bogotá: ICFES-Universidad Pedagógica Nacional). Con un prefacio de Marco 
Palacios y una introducción y un apéndice bibliográfico de Gonzalo Cataño. Trad. de I. E. Castaño y G. Cataño.

1990 [1892 y 1918] Montesquieu y Rousseau: precursores de la sociología, con un prólogo y un apéndice bibliográfico de Gonzalo Cataño, y notas de Armand Cuvillier (Bogotá: Asociación Colombiana de Sociología y Universidad Nacional de Colombia). Trad. de Rubén Sierra Mejía.

1993 [1972] Escritos selectos (Buenos Aires: Ediciones Nueva Visión). Selección de textos a cargo de Anthony Giddens, precedidos de un comprensivo ensayo sobre el pensamiento de Durkheim. Trad. del inglés de Ricardo Figueroa. Además de extractos de las obras mayores, este volumen contiene una interesante muestra de Durkheim como autor de reseñas de libros.

1996 [1896-1902] Clasificaciones primitivas y otros ensayos de antropología positiva (Barcelona: Ariel). Con una introducción de M. Delgado Ruiz. Trad. de M. Delgado Ruiz y A. López Bargados. Contiene cuatro ensayos de antropología social publicados originalmente en L'Année Sociologique: "Sobre algunas formas primitivas de clasificación», "Sobre la definición de los fenómenos religiosos», "La prohibición del incesto» y «Sobre el totemismo».

\section{ENSAYOS}

1904 [1903] «Sociología y ciencias sociales» (con Paul Fauconnet), Revista de Legislación y Jurisprudencia (España), febrero-abril. Una segunda traducción, a cargo de Santiago González Noriega, se encuentra en Emile Durkheim, Las reglas del método sociológico y otros escritos sobre filosofía de las ciencias sociales (Madrid: Alianza Editorial, 1988), pp. 244-287.

1911 [1909] "Sociología y ciencias sociales», en H. Bouasse, P. Delbet y E. Durkheim et al., Del método de las ciencias (Madrid: Librería Gutenberg de José Ruiz), pp. 326-353. Trad. de M. Rodríguez Navas. Publicado nuevamente en Emile Durkheim, Sociología (Córdoba, Arg.: Editorial Assandri, 1961), pp. 171-194.

1959 "La democracia», Revista Mexicana de Sociología, vol. XXI, n. ${ }^{\circ}$ 3, pp. 819-830. Publicado por primera vez en español a partir de un texto inédito transcrito por Raymond Lenoir. Trad. de Óscar Uribe Villegas.

1962 "La sociedad política», Revista Mexicana de Sociología, vol. XXIV, n. ${ }^{\circ} 1$, pp. 9-13. Publicado por primera vez en español a partir de un texto inédito transcrito por Raymond Lenoir. Trad. de Óscar Uribe Villegas.

1971 [1903] «De ciertas formas primitivas de clasificación» (con M. Mauss), en Marcel Mauss, Obras (Barcelona: Barral Editores), vol. II, pp. 1373. Trad. de Juan Antonio Matesanz.

1971 [1913] «Nota sobre la noción de civilización» (con M. Mauss), en Marcel Mauss, Obras, ed. cit., vol. II, pp. 265-268. Trad. de Juan Antonio Matesanz. 
1976 [1904] «La élite intelectual y la democracia», en Emilio Durkheim, Educación como socialización (Salamanca: Ediciones Sígueme), pp. 8385. Trad. (del italiano) de Alfonso Ortiz García.

1976 [1914] «El dualismo de la naturaleza humana y sus condiciones sociales», en Emilio Durkheim, Educación como socialización, ed. cit., pp. 37-51. Trad. (del italiano) de Alfonso Ortiz García.

1987 [1897] «La concepción materialista de la historia» (con una nota introductoria de Gonzalo Cataño), Revista de la Universidad de Antioquia, n. 212 (Medellín), abril-junio, pp. 10-15. Trad. de Inés E. Castaño. Una segunda traducción, a cargo de Santiago González Noriega (Madrid, 1988), se encuentra en Emile Durkheim, Las reglas del método sociológico y otros escritos..., ed. cit., pp. 224-233.

1988 [1904-1916] «Siete textos inéditos de Durkheim sobre educación y pedagogía» (con una nota introductoria de Gonzalo Cataño), Revista Colombiana de Educación, n. ${ }^{\circ}$ 19, Bogotá, pp. 7-64. Trad. de Inés E. Castaño y Gonzalo Cataño. Incluye: «La educación como fenómeno social», "Infancia», "La pedagogía de Rousseau», "Debate sobre la educación sexual», "Debate sobre los internados y la escuela nueva», "La familia, la escuela y la autoridad» $\mathrm{y}$ «La escuela del mañana».

1988 [1898] «Prefacio al volumen primero de El Año Sociológico», en Emile Durkheim, Las reglas del método sociológico y otros escritos..., ed. cit., pp. 215-223. Trad. de Santiago González Noriega.

1988 [1899] «Prefacio al volumen segundo de El Año Sociológico», en Emile Durkheim, Las reglas del método sociológico y otros escritos..., ed. cit., pp. 234-240. Trad. de Santiago González Noriega.

1988 [1899] «Nota sobre la morfología social», en Emile Durkheim, Las reglas del método sociológico y otros escritos..., ed. cit., pp. 241-243. Trad. de Santiago González Noriega.

1988 [1903] "La historia y las ciencias sociales», en Emile Durkheim, Las reglas del método sociológico y otros escritos..., ed. cit., pp. 288-291. Trad. de Santiago González Noriega.

1988 [1908] «Debate sobre la explicación en historia y en sociología», en Emile Durkheim, Las reglas del método sociológico y otros escritos..., ed. cit., pp. 292-312. Trad. de Santiago González Noriega.

1988 [1917] «Una definición de la sociedad», en Emile Durkheim, Las reglas del método sociológico y otros escritos..., ed. cit., p. 313. Trad. de Santiago González Noriega.

1990 [1890] "Los principios de 1789 y la sociología», Investigar, n. ${ }^{\circ} 3$, y Argumentos, n. ${ }^{\text {os }} 22-23$ (Bogotá), enero, pp. 17-22. Trad. de Rodrigo Alzate.

1992 [1918] «La vida universitaria en París», Revista Colombiana de Educación, n.o 25 (Bogotá), pp. 110-128. Trad. e introducción de Inés E. Castaño. 
1994 [1918] «La enseñanza moral en la escuela primaria», Revista Colombiana de Educación, n. ${ }^{\circ} 29$ (Bogotá), pp. 71-90. Trad. e introducción de Inés E. Castaño.

1997 [1908] «Debate sobre la economía política y las ciencias sociales», Hojas Económicas, n. ${ }^{\circ 5} 6$ y 7 (Bogotá), febrero, pp. 143-147. Trad. e introducción de Inés E. Castaño. 


\section{TEXTO CLÁSICO}

